\title{
Transitions in Cooperative Labour and the Constraints to the Adoption and Scaling-Up of Labour Intensive Agricultural Technologies
}

\author{
David Natcher ${ }^{1}$, Erika Bachmann ${ }^{1}$, Mohamed Nasser Baco ${ }^{2}$, Suren Kulshreshtha ${ }^{1}$, Jeremy Pittman ${ }^{3} \&$ Derek Peak $^{1}$ \\ ${ }^{1}$ University of Saskatchewan, Canada \\ ${ }^{2}$ University of Parakou, Benin \\ ${ }^{3}$ University of Waterloo, Canada
}

Received: April 26, 2018 Accepted: May 11, 2018 Online Published: May 25, 2018

doi:10.5539/sar.v7n3p71 URL: https://doi.org/10.5539/sar.v7n3p71

\begin{abstract}
The research presented in this paper stems from a collaboration between researchers in the Benin Republic, Nigeria and Canada who are examining the opportunities to enhance the sustainable production of under-utilized indigenous vegetables through the micro-dosage of synthetic fertilizer. Because micro-dosing is a labour intensive technology, and is time sensitive in application, we sought to better understand how the availability of labour, as affected by changes in cooperative networks, might affect adoption and scaling up opportunities. The systems of cooperative labour described in this paper reflect the culture and traditions of the Betammaribe people, residing in the village of Koumagou B in northwest Benin. Our results indicate that cooperative labour systems among the Betammaribe are in transition and are being influenced by seasonal migration, the financial demands of formal education, the use of oxen by those with relative wealth, and off-farm employment. These pressures have led to the atomizing of Koumagou B households and a concomitant decline in the availability of cooperative labour. Interventions designed to improve the livelihoods of smallholder farmers must not inadvertently perpetuate social and economic inequalities or disadvantage those most vulnerable. It is this possibility that warrants careful consideration as we contemplate the benefits of adopting and scaling-up new agricultural technologies in the future.
\end{abstract}

Keywords: Benin, labour exchange, micro-dosing, socio-economic inequality

\section{Introduction}

The availability of agricultural labour has shown to be a critical factor for the adoption of new agricultural technologies and often serves as an operative constraint to farming systems in Africa (Larson \& Gurara, 2013; Marenya \& Barrett, 2007). This is particularly true during critical periods of production when labour is in most demand (Palm, Myers \& Nandwa, 1997; Mignouna Manyong, Rusike, Mutabazi \& Senkondoet, 2011; Bachman et al., 2016), or when adoption involves labour intensive technologies, such as organic or inorganic fertilizer applications (Palm, et al., 1997) and other soil conservation investments (Lee, 2005).

Some have argued that systems of cooperative labour are capable of overcoming short-term labour constraints in ways that facilitate the adoption of labour intensive technologies. Adapted over time, cooperative labour systems ease labour shortages and relax the labour constraints that can impede the adoption and scaling up of new agricultural technologies (Kirinya, Taylor, Kyamanywa, Erbaugh \& Bonabana-Wabbiet, 2013). Such systems exist among smallholder farmers throughout the world and have been described in detail for Sub-Saharan Africa, including south-western Ethiopia (Bartels, 1977), south-eastern Cameroon (Geschiere, 1995), eastern Uganda (Shiraishi, 2006), Zimbabwe (Worby, 1995), Nigeria (Stone, Netting \& Stone, 1990), Tanzania (Ponte, 2000), the Democratic Republic of the Congo (Suehara, 1983, 2006), and Sudan (Barth, 1967). These accounts often depict cooperative labour systems as driven by a sense a mutual aid and reciprocal behaviour.

Much of the current research conducted on cooperative labour has been influenced by the seminal works of Erasmus (1956) and Moore (1975), who both offered simple, yet useful, typologies of cooperative labour systems. For Erasmus (1956), cooperative labour can be divided into two types: exchange labour, which relies upon strict reciprocity of labour and sometimes the provisioning of simple meals; and festive work parties, which require the host to provide more elaborate food and drink but do not require reciprocal labour commitments. Moore (1975), while respecting this underlying typology, preferred to call these two types of cooperative labour simply 
'reciprocal' and 'non-reciprocal', as he believed the true difference lay in the level of labour-based reciprocity.

In some regions of Africa, the prevalence of socio-economic inequality have altered or displaced traditional systems of cooperative labour. For example, Swindell (1985) suggests that a transition has been occurring in cooperative labour systems throughout Africa as a result of migration, a growing landless proletariat, the introduction of full-time, off-farm employment, and the commodification of the economy. In light of these changes, it is necessary to understand how these conditions affect the supply of local labour before proposing any new agricultural technologies or attempting to identify user groups with high adoption potential (Dreschsel, Olaleye, Thiombiano, Barry, \& Vohland, 2005). If local labour supply is limited, or if new technologies demand intensive labour inputs, caution must be exercised before introducing new technologies that only add to the labour burden of farming households (Drechsel et al., 2005).

The research presented here stems from a collaboration between researchers in the Benin Republic, Nigeria and Canada who are examining the opportunities to enhance the sustainable production of under-utilized indigenous vegetables through the minimal use of synthetic fertilizer, a process referred to as Micro-Veg technology. Micro-dosing involves the placement of small amounts of fertilizer at the base of plants at the time of seeding or soon after germination. The aim of this project is to accelerate the adoption of fertilizer micro-dosing to enhance the production of indigenous vegetables (e.g., amaranth, African eggplant, fluted gourd, African basil) leading to improved food and nutritional security, while contributing to the economic empowerment of resource constrained farmers. The ultimate scaling up objective is to reach 250,000 farmers in 51 locations across Benin and Nigeria. Given that micro-dosing is a labour intensive technology, and is time sensitive in application (Camara, Camara, Berthe \& Oswald, 2013), we sought to better understand how the availability of labour, as affected by changes in cooperative networks, might affect the scaling up of the Micro-Veg technology. Our analysis was motivated by an understanding that interventions designed to improve the livelihood conditions of farmers must not inadvertently perpetuate existing conditions of social and economic inequality. It was this possibility that warranted careful consideration as we contemplated the risks and benefits of scaling-up new agricultural technologies.

\section{Study Area}

The study area for this research was the village of Koumagou B, which is located within the commune of Boukombe, in the Atacora department of northwest Benin (Figure 1). Koumagou B is comprised of five hamlets - Koumagou Centre, Yatera, Koutannagou, Koucangou, and Kouyiéndagou - whose residents are united by kinship, and recognize each other as descendants of the original village founder (Joffroy and Djanguenane, 2005). The area surrounding Koumagou B consists of valleys and hills, rocky cliffs and plateaus (Avohou and Sinsin, 2009). The climate is Sudano-Sahelian, with a rainy season stretching from June to October and a dry season lasting from November to May (Aregheore, 2009). Climate change is affecting the timing and duration of the rainy season, creating unpredictability and stress for farmers who rely solely upon rain-fed irrigation. Farming in the village is primarily subsistence-based and includes the production of sorghum, millet, fonio, rice, beans and tubers such as yam. Most farm labour is done by hand, with little mechanization. Synthetic fertilizer is used to a limited extent on some crops (particularly maize), depending upon availability and affordability (Bachmann et al., 2016). The application of organic fertilizer (manure) is typically constrained by the size and number of animals owned by village households. 


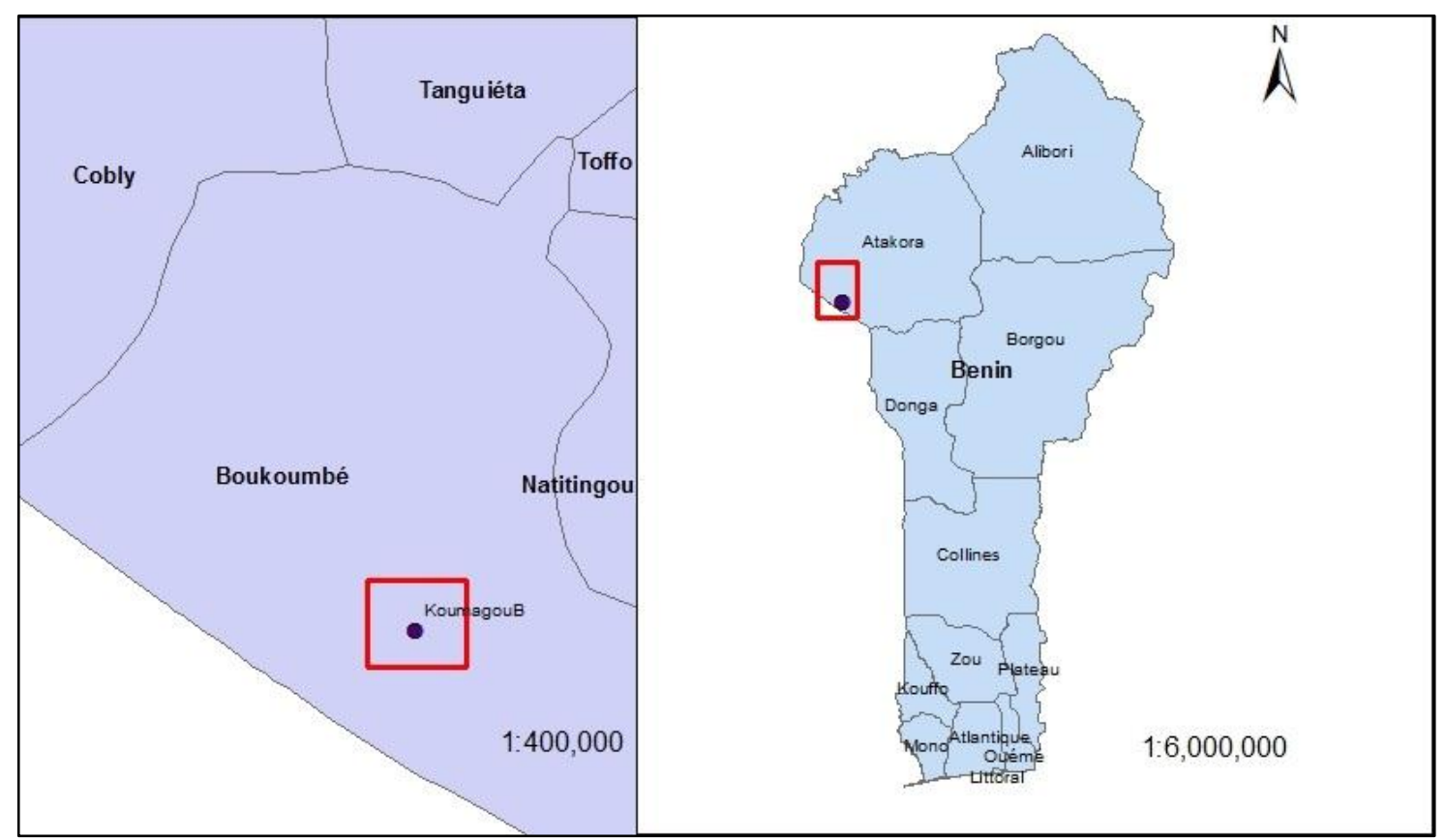

Figure 1. Location of Koumagou B, Benin

Field work was conducted during an initial 3-month exploratory field season between May and August 2014, followed by a second 11-month field season from June 2015 to May 2016. Our research was informed by grounded theory and involved a mixed methodology consisting of a village census, a Principle Component Analysis, key informant interviews, focus groups, and participant observation.

A village census was conducted with each head-of-household in the village. The census was used to enumerate household labour, assets, and education. Survey questions addressed the participation of household members in reciprocal and non-reciprocal labour activities. Both classifications were considered useful for understanding and qualifying the current state of cooperative labour at the village level. In total, 92 out of 98 households were surveyed (94 percent); representing a survey population of 768 residents.

To evaluate the potential impact of socio-economic status upon one's involvement in cooperative labour, a Principal Component Analysis (PCA) was used to develop a household index of socio-economic status. PCA is a multi-variate statistical technique that is used to reduce the dimensionality of a group of variables while still capturing variation among the group. For this analysis, the variables included household labour, land ownership, education, and durable household assets as proxies for socio-economic status. This approach has been used in various settings where income data are difficult to come by or simply unreliable.

Fourteen key informant interviews were conducted with village residents. An initial participant list was co-developed with our local research collaborators. However, a schemata was used to help ensure a representative cross-section of the village population according to age, gender, household composition, and marital status. This sample included male and female respondents who were married in polygamous households $(3 \mathrm{M}, 1 \mathrm{~F})$; male and female respondents who were married in monogamous households $(2 \mathrm{M}, 2 \mathrm{~F})$; male and female respondents who had never been married $(1 \mathrm{M}, 1 \mathrm{~F})$; and male and female respondents who were widowed $(2 \mathrm{M}, 2 \mathrm{~F})$.

Two focus groups involving village farmers were also conducted. Focus group discussions explored the changes occurring in cooperative labour and the demands or drivers that are influencing those changes. In addition to these formal exchanges, 14 months of living in Koumagou B allowed for countless interactions and opportunistic conversations that further informed our analysis. However, the exchange of information between villagers and members of the research team was at times challenging. Because villagers often express information by way of parables, metaphors and allusions, the information being provided is best understood by someone with an emic knowledge of Betammaribe culture and society. In addition, the Ditammari language is intuitive where only a single word may be spoken but the rest of the phrase is understood at least by other Betammaribe. Accordingly, members of the Canadian and Beninese research team worked closely with village collaborators to ensure what 
we were learning through our interviews and focus groups was not misconstrued.

It is also important to note that in general, the Betammaribe are reluctant to share information with outsiders. Padenou and Pastor-Barrué (2006), found this to be the case when studying the architectural significance of the tatas, and encouraged other researchers to consider this fact before conducting any research with the Betammaribe. This was indeed our experience, where gender and culture intersected to create unspoken barriers. This is where 14 months of participant observation and the less formalized, though equally important, aspects of sustained field work proved invaluable. The ultimate success of this research was based on the trust and personal relationships that developed through the course of the fieldwork.

\section{Traditional Cooperative Labour Systems}

Agricultural labour exchange not only in Koumagou B, but also more generally amongst the Betammaribe, is comprised of multiple systems organized according to age, gender, level of reciprocity, season, and time of day. Labour strategies are further differentiated by the social and economic status of households. One of the major systems of labour exchange in Koumagou B is referred to as Tachaata and stems from the traditional system of marriage within Betammaribe society. Historically, marriage was arranged soon after birth. A father would bring a white baby chick to the family of his potential daughter-in-law, who may have just been born. If the chick is accepted, the marriage arrangement was agreed upon. If the chick survived and produced eggs, the marriage was deemed to have a promising future. In the following years, the family of the prospective groom, along with extended kin, would work each year on a specific set of agricultural tasks for their future in-laws. In addition to providing labour, the groom's family would bring food stuffs to the girl's family, to ensure the child was well nourished. This system of exchange can last as long as 10 years.

For the general adult population in Koumagou B (i.e., those who have undergone their initiation ceremony), a system of reciprocal labour exchange occurs during the morning hours. This system is called Tapikantouanta (meaning morning mutual assistance) or alternatively, Tanananta. This is a small rotational group involving 2 to 5 people who take turns working each other's fields. For their efforts, the host provides a thin porridge to the workers during the work period. The relatively small size of the group means a more frequent work rotation with labour being available every few days. This particular system is closest to the pure exchange labour of Erasmus (1956) and the reciprocal cooperative labour system discussed by Moore (1975).

Group formation in the Tapikantouanta system is based on physical and relational proximity. Physical proximity allows for an early start time and relational proximity fosters productive work environments. For example, a young woman explained that for Tapikantouanta, a woman would choose her closest friend (in a relational sense) with whom to work.

...you choose your closest friend, and you work together, and another chooses their closest friend, and they work together. Because if there is someone among you who doesn't get along properly with the others, the work is not going to function well. If there are problems between you, the work will not move ahead.

The composition of the group may change for different reasons: it may be affected by seasonal work migration in the case of men, by pregnancy in the case of women, or by illness. However, the importance of trustworthiness in the composition of the work group is considered a determinant for cooperative group membership. Farmers choose to work with those who can 'keep the secrets of the small group', and will not divulge that which has been said while working.

In the afternoon, after workers have had time to rest following Tapikantouanta, and have eaten a mid-day meal at their own homes, workers would assemble into Koutouangou groups, which translates roughly to 'large mutual assistance'. Koutouangou is a type of rotational labour exchange that can involve between 10 to 20 workers. Like the Tapikantouanta system, Koutouangou is also reciprocal. However, in this system the host must also provide a basic meal at the end of the work day. Those with economic means would offer meat (ideally pork, goat or beef, with poultry as a secondary option) in addition to a grain. Those with less economic means tend to offer small dried fish or fried cheese. Both men and women participate in Koutouangou, although labour activities are gender specific.

Koutouangou is organized under the guidance of the eldest male or female in the group. While the personal autonomy of individual Otammari is highly revered, deference is offered to those who are older, i.e., those who have done their initiation ceremony before you. One villager described how the eldest directs the efforts of the group, ensuring that the work schedule aligns with other social obligations and is adjusted to the uncertainties of weather. However, this same villager made clear that the eldest was "not a chief" in the sense of being able to dictate the work of others, but rather, he or she was only put in charge of the schedule. 
If the Koutouangou fails to satisfy the labour needs of the host, he or she can invite the Koutouangou group back for additional work by hosting a festive work party. This system is referred to as Diyiyi, meaning 'to invite', and is consistent with the 'festive work party' described by Erasmus (1956) or 'non-reciprocal cooperative labour' category of Moore (1974). Villagers described this process by using the analogy of the tontine, or the informal rotating savings and credit association that is popular throughout West Africa (see Sommerfeld, Sanon, Kouyate, and Sauerborn 2002, for an overview of such associations in the West African context). "Koutouangou is like a tontine. If your tontine had already passed and you still need something done, then you do Diyiyi." In this manner, they are distinguishing between the rotating 'investment' nature of Koutouangou, and the one-off, 'payment' nature of Diyiyi (even though in this case they will be working with the same working group members).

More commonly, Diyiyi is used by farmers as an ad-hoc way of gathering a large work party from throughout the village. In this case a farmer spreads word, often by going door to door, that he or she would be hosting a work party. Depending on the amount of work to be done, well over 20 people may attend, although not all contribute equally to the labour but rather may be used by some (e.g., very young and the elderly) as an opportunity to socialize with neighbours and enjoy the food and drink that are provided by the host. In contrast with the standard fare offered at the end of Koutouangou, the host is expected to provide a more lavish meal, as Diyiyi is not a form of reciprocal labour exchange. The special fare is acknowledgement of non-reciprocal cooperation. Tchouc, the traditional fermented sorghum beer, is a requisite offering, though stronger forms of alcohol, including imported liquors, have also become common. The socialization aspect also performs an important function in the coordination of the cooperative labour system in general. A Diyiyi provides the opportunity for people to meet, interact and discuss forming a Koutouangou group for the afternoons.

While meat, ideally pork, goat or beef is most valued, those with less means give what they have in hopes of attracting sufficient labour. Whether providing meat or less valued forms of sustenance, the host is expected to thank the participants for their labour; "thank you for yesterday" or "thank you for the other day" signifying their appreciation well after the work was completed. Verbal acknowledgement is important to signify the lasting impression and is considered essential for maintaining good working relationships.

Another form of cooperative labour is referred to as Takinta and is employed specifically for the harvest and processing of fonio in September/October. Fonio, a grain indigenous to West Africa, holds a special place in Betammaribe society, and its cultivation embodies very distinct responsibilities according to age and gender. Only men can sow the fonio (the seeds come from the 'male' granary which only the man has access to) and only men can cut the fonio at harvest time. Older women are considered specialists for weeding throughout the season. At harvest time, women of all ages gather and sort fonio sheaves into piles. After the fonio has dried in the fields and is brought to the threshing floor, children are enlisted to crush the fonio beneath their feet to release the grain. Women then pound the fonio to remove the husk and sift and wash the grain. The Takinta system demonstrates the unique age and gendered dimensions of cooperative labour.

It is also common for Betammaribe youth to participate in a system called Tatouanta (meaning mutual assistance) or more precisely Tabikantouanta (Tatouanta for the children). Prior to undergoing their initiation into adulthood, youth work the village fields. Boys and girls work separately, and receive informal instruction and education on their appropriate roles as adults in Betammaribe society. Tatouanta continues until one is initiated into adulthood, which is not fixed by age but determined by the size and health of the child, and the timing of initiation ceremonies, including those that mark permissible sexual relations.

\section{Changes in Cooperative Labour}

As early as the 1950s, Mercier (1968) found that the traditional form of arranged marriage was decreasing in prominence among the Betammaribe due to the growing influence of the European economic system that commoditized labour. An important example of this tendency is the manner in which young women in Koumagou B have used their system of labour exchange to gain purchasing power in the emerging monetary economy. A widowed woman, approximately 45 years of age, attributed the change to the advent of girls attending school in greater numbers and choosing to delay marriage. Others felt that Tachaata has been discontinued, or more accurately, "broken because one no longer pays a bride price for the wife."

The material demands of formal education-school supplies, school uniforms-requires cash. Young women have drawn upon the organizing principles of cooperative labour to harness their earning power and engage with the market economy, an economy that provides the financial means to purchase fabric for clothes, school supplies and the ubiquitous cell phone and corollary phone credit. Farmers are now expected to pay groups of young women for their labour. The amount paid is not necessarily determined by the work achieved, but rather is a set 
amount, which at the time of this research was 4500 CFA. Adapted in this way young women are using cooperative labour to meet the current demand for wage income.

As the system of arranged marriages declined, Tachaata has also transformed into Koutouangou. While still maintaining many of its traditional qualities, including kin-based and reciprocal, the frequency that work groups are formed has declined as more households rely on oxen, and to a lesser extent, mechanized technologies to meet their tilling needs. Of the 92 households surveyed, 12 (13\%) owned oxen. As oxen and plough offer a more efficient labour saving option, the use of Koutouangou in particular has become less common. Of the 92 households surveyed, 38 household $(41 \%)$ reported participation in Koutouangou.

Table 1. Participation in Koutouangou

\begin{tabular}{llllll}
\hline Participation in Koutouangou & \multicolumn{7}{l}{} \\
\hline & $\begin{array}{l}\text { Koumagou Centre } \\
\text { (Hamlet 1) }\end{array}$ & $\begin{array}{l}\text { Yatera } \\
\text { (Hamlet 2) }\end{array}$ & $\begin{array}{l}\text { Koutannagou } \\
\text { (Hamlet 3) }\end{array}$ & $\begin{array}{l}\text { Koucangou } \\
\text { (Hamlet 4) }\end{array}$ & $\begin{array}{l}\text { Kouyiéndagou } \\
\text { (Hamlet 5) }\end{array}$ \\
\hline N-Households & 35 & 13 & 9 & 16 & 19 \\
\% of Koumagou B Households & $38 \%$ & $14 \%$ & $10 \%$ & $17 \%$ & $21 \%$ \\
$\begin{array}{l}\text { Number and (\%) of households } \\
\text { participating in Koutouangou }\end{array}$ & $6(17 \%)$ & $2(15 \%)$ & $6(67 \%)$ & $11(69 \%)$ & $13(68 \%)$ \\
\hline
\end{tabular}

It is not only oxen but also the advent of wage employment, which has also been attributed to the decline in the Koutouangou system. One man, in his early 50s, married with two wives and 17 children, noted that Koutouangou, and cooperative labour in general, has:

“...decreased... Because today people use machines to till the soil, the oxen as well. And lots of people don't like doing Koutouangou because they have money now. ... They do jobs."

The pressure to earn cash from employment, as opposed to relying upon reciprocal labour exchange, has affected the general availability of labour and the perpetuation of reciprocal labour exchange. This is most pronounced among young men who have the additional pressures of paying for school. Unlike girls, boys in Benin are required to pay school fees for secondary grade levels. With few local wage earning opportunities, young men often migrate to neighbouring communes, particularly Natitingou and Bembèrèkè, to find employment. One young man, unmarried yet initiated into adulthood, attributed the 'rural exodus' to wage seeking opportunities:

"Our area here, there aren't jobs (paa). If I stay here, just until the end of the rainy season, I wouldn't have enough money to buy school supplies. Here, you can't work at someone's place and have money very quickly for your work. He [the employerlfarmer] is going to say wait until he goes to sell his crops."

An older farmer similarly acknowledged this economic reality when admitting "we don't have the money here to pay people." With money in short supply, most farmers consider their opportunity costs, preferring to use the little money they have to grind millet and buy ingredients for sauce. After these expenditures, farmers acknowledge that there is rarely enough money left to pay people to work in the fields.

These changes have in many ways disadvantaged the relatively poor in the village who are now challenged to attract needed labour. For those farmers struggling with cash flow, or unable to afford lavish meals for work parties, using reciprocal exchange labour was their best option for attracting labour. For example, a young woman, when asked how she acquires agricultural labour, said that after having relied upon internal household labour, she would then look for cooperative labour, and only after these options were exhausted, would she look to hire someone and pay them, asking rhetorically "does one want to let go of money?"

Other farmers stated that with the decline of Koutouangou, Diyiyi (non-reciprocal exchange labour/festive labour) has become more common. As noted above Diyiyi requires a more lavish and expensive meal to attract labourers but does not require reciprocal labour obligations. Many farmers noted that in the past they would rely on Koutouangou to attract needed labour but now it is more common for those with the financial means to host a Diyiyi. Geschiere (1995) notes that this type of transformation in cooperative labour groups is akin to hired labour gangs that have become common in Cameroon. In that case, wealthier farmers have been able to manipulate what were reciprocal labour systems by providing a wage or lavish meals as compensation. Swindell (1985) also found that conditions of economic differentiation enable wealthier farmers to appropriate the labour of poorer farmers through the provisioning of meals. In these cases the socio-economic status of farmers influences the pattern of labour exchange with the more wealthy utilizing festive and wage labour, while economically disadvantaged farmers must rely on reciprocal labour exchange (Chibnik and de Jong, 1989). Research conducted in other parts of the world demonstrate similar transitional complexities (Barth, 1967; 
Takasaki et al., 2014; Worby, 1995). In Peru, for example, the reciprocal labour system of ayni is decreasing in importance as the opportunity cost of cooperative labour increases (Mitchell,1991).

In our research, an elderly man neatly summed up the major changes regarding the system of mutual assistance:

"Yes, there really has been a change. The children don't work anymore. Some plow with oxen; others use invitation (diyiyi) only, and lots no longer organize themselves into groups to work."

When we divided the households into quartiles based upon socio-economic status (SES), the highest two quartiles did indeed show the lowest participation in Koutouangou. In fact, none of the households in the two highest quartiles used Koutouangou (Table 2).

Table 2. SES of Village Households

\begin{tabular}{lccc}
\hline \multicolumn{3}{c}{ Socio-Economic Status of Village Households } \\
\hline & Mean & Proportion & St Dev. \\
\hline Household Demographics $(N-92)$ & & & \\
Gender of Respondent/Head & & & \\
$\quad$ Male & & 0.90 & \\
$\quad$ Female & 0.10 & 12.35 \\
Age of HH Head & 41.01 & & 3.84 \\
Household Labour & 4.06 & & 1.11 \\
Total Cultivable land (ha) & 2.41 & & \\
Some education=1 Illiterate=0 & & 0.30 & 18.28 Max \\
Socio-Economic Status & 8.21 & 1.93 Min \\
\hline
\end{tabular}

Off-farm earning opportunities for some households has created greater socio-economic differentiation within the hamlets. For those with greater financial resources or sources of income outside agriculture, the higher opportunity cost of their time and the lower opportunity cost of cash influences the extent to which the labour of others is reciprocated. In this case, non-reciprocal cooperative labour (Diyiyi) or hiring wage labour provides greater flexibility and allows wealthier landowners to pursue other more remunerative activities. A man with a job as a motorcycle taxi driver and two wives who both had sources of income outside of agriculture, noted:

"Someone can come and ask for some work, and you give a portion [of your field] and discuss the price. If he is satisfied, he works and I pay him."

In contrast, a young woman in a female-headed household with no off-farm income, explained:

"Before, you would invite people and lots of people came. But today, lots don't come. They always wait for you to find them something. Because, if they know that you are going to prepare them something to eat, certain people say to themselves "I have already eaten at my place, what am I going to find elsewhere?" They ask themselves the question "Am I going to work for the pâte or the sauce?" Those that are poor have difficulty working in their field."

Reciprocal cooperative labour is theorized to function best in groups with limited socio-economic differentiation (Erasmus, 1956; Swindell, 1985). At an intuitive level, the farmers in Koumagou B knew this. One woman, when asked who she works with in the system of cooperative labour, responded "One must choose someone who has the same difficulty as you." Whereas reciprocal cooperative labour once helped to ensure resources flowed from the relatively rich to the poor, promoting equality of productive resources within the society, now farmers, particularly widows and the economically marginalized, complain that the system no longer works for them. Many noted that in the past, the poorest of the village were helped through the system of mutual assistance.

“... the objective was to help each other. There were certain neighbours who didn't manage to work in their field. Or they didn't have the time to work in their field. Thus the system facilitated helping each other."

People now complain that other farmers are increasingly calculating regarding participation in cooperative labour systems. This was a sentiment shared across socio-economic groups. A married man of higher SES, when asked if the systems that existed before were designed to help each other:

"Yes, to help each other and that is what gave joy in the village. The poorest could benefit from services of their brothers in the village. Before, there was joy. The poor or the rich helped each other, without problem... [but now] if you don't have the means, you can't benefit from the services of others."

When asked about the changes that are occurring in cooperative labour, a middle-aged male farmer said that 
people no longer want to work with their neighbours because they do not want their neighbours to have the same "riches" as them. Others similarly noted that due to economic inequality between households there is an unwillingness for villagers to work together:

"Because they think that by helping the other, the other becomes stronger. Whereas it's mutual. Normally, you should be at the same level, like our parents were. But presently, we have lost that."

\section{Discussion and Conclusion}

The systems of cooperative labour described in this paper reflect the culture and traditions of the Betammaribe people. These systems persist and continue to evolve under the influence of various globalizing processes. The transition that is occurring in their cooperative labour systems reflects the dynamism of Betammaribe culture and the engagement of Koumagou B households with the emerging demands of a monetary market system, formalized education, and general social change. These pressures will continue to shape the nature of cooperative labour among the Betammaribe. The system of Koutouangou, or the afternoon system of mutual assistance, reflects a time when arranged marriages and bride prices led men and their neighbours to rally together and work on the fields of the future in-laws. Koutouangou itself, however, is threatened by the increasing prominence of wage labour, oxen that plough the field where once men tilled together by hand, seasonal migration, and the increasing popularity among those with the financial means to host Diyiyi, festive work parties. Tatouanta, once reserved for youth destined to marry soon after initiation into adulthood, is now used by young women to earn money to pay for items required for their formal education. The remuneration offered to these young women straddles the traditional systems of mutual assistance and a new system based on gendered solidarity and the commodification of their labour. This trend may foreshadow a wider schism in the traditional labour system, as educated young women leave the fields to work in different sectors, as young men transition to wage labour (agriculture or otherwise), and as the elderly left in the village are no longer able to work the land in cooperative labour systems.

Others who have studied cooperative labour in Africa note the possible coexistence of cooperative labour systems and the commodification of labour (Netting, Stone \& Stone, 1989; Takasaki, Coomes, Abizaid \& Brisson, 2014; Worby, 1995). These authors stress the importance of avoiding the temptation to view the evolution of cooperative labour on a continuum from traditional reciprocal exchange to modern commoditized labour. One should not view these changes as abrupt breaks with tradition but rather a transition determined partly by localized and regional norms together with other societal pressures.

Yet cooperative labour systems that rely on mutual trust, reciprocity, and physical and relational proximity have traditionally bound Koumagou B households through webs of mutually supportive relationships. Viewed in this light, elements that disrupt these systems migration for seasonal work, the demands of modern schooling, the use of oxen privileged by the wealthier few, off-farm employment have nonetheless contributed to the atomizing of Betammaribe society. It is tempting to offer up cooperative labour as a means of harnessing the power of community solidarity for overcoming the constraints associated with the adoption and scaling-up of new agricultural technologies. However, as researchers and practitioners, we must remain cognizant of the rapidly changing nature of social cooperation in the face of market penetration, the commodification of labour, and the general complexity of gender and labour relations. These considerations are critical if we are to enhance rather than hinder the livelihoods of those we hope to aid through our research and extension efforts.

\section{Acknowledgements}

Financial support for this research was provided by the Canadian Department of Foreign Affairs, Trade and Development (DFATD), International Development Research Centre (IDRC) Canadian International Food Security Research Fund (CIFSRF) Project 106516. We gratefully acknowledge the support and contributions of Kevin Thiessen, Innocent Butare, Anthony Kimaro and N'dah M'po Pascal.

\section{References}

Aregheore, E. M. (2009). The Republic of Benin. (Country pasture/Forage resource profiles). FAO. Retrieved from http://www.fao.org/ag/agp/AGPC/doc/Counprof/Benin/Benin.htm\#3climate

Avohou, H. T., \& Sinsin, B. (2009). The Effects of Topographic Factors on Aboveground Biomass Production of Grasslands in the Atacora Mountains in Northwestern Benin. Mountain Research and Development, 29(3), 250-254. https://doi.org/10.1659/mrd.00028.

Bachmann, E., Natcher, D. C., Kulshreshtha, S., Baco, M. N., Akponikpe, P. B. I., \& Peak, D. (2016). Profitability and Institutional Constraints to the Adoption of Fertilizer Microdosing in Northwest Benin. Sustainable Agriculture Research, 5(3), 11-20. https://doi.org/10.5539/sar.v5n3p11. 
Bartels, L. (1977). Dado: A Form of Cooperation on Equal Terms among the Macha Oromo of Ethiopia. Anthropos, 72(3/4), 497-513.

Barth, F. (1967). Economic Spheres in Darfur. In R. Firth (Ed.), Themes in Economic Anthropology (pp. 143-174). London: Tavistock Publications Ltd.

Camara, B. S., Camara, F., Berthe, A., \& Oswald, A. (2013). Micro-dosing of Fertilizer - A Technology for Farmers' Needs and Resources. International Journal of AgriScience, 3(5), 387-399.

Chibnik, M., \& De Jong, W. (1989). Agricultural Labor Organization in Ribereño Communities of the Peruvian Amazon. Ethnology, 28(1), 75-95. https://doi.org/10.2307/3773643.

Dreschsel, P., Olaleye, A., Thiombiano, L., Barry, B., \& Vohland, K. (2005). Adoption Driver and Constraints of Resource Conservation Technologies in sub-Saharan Africa, pp. 1-21.

http://www.iwmi.cgiar.org/africa/west_africa/projects/AdoptionTechnology/AdoptionConstraints-Overview. pdf (online).

Erasmus, C. J. (1956). Culture Structure and Process: The Occurrence and Disappearance of Reciprocal Farm Labor. Southwestern Journal of Anthropology, 12, 444-469. https://doi.org/10.1086/soutjanth.12.4.3629069.

Geschiere, P. (1995). Working Groups or Wage Labour? Cash-crops, Reciprocity and Money among the Maka of Southeastern Cameroon. Development and Change, 26(3), 503-523. https://doi.org/10.1111/j.1467-7660.1995.tb00563.x

Joffroy, T., \& Djanguenane, N. (2005). Koutammakou, le pays des Betammaribe: "Ceux qui façonnent la terre." CRATerre éditions.

Kirinya, J., Taylor, D. B., Kyamanywa, S., Erbaugh, J. M., \& Bonabana-Wabbi, J. (2013). Adoption of Integrated Management Technologies in Uganda: Review of Economic Studies. International Journal of Advanced Research, 1(6), 401-420.

Lee, D. (2005). Agricultural Sustainability and Technology Adoption: Issues and Policies for Developing Countries. American Journal of Agricultural Economics, 87(5), 1325-1334. https://doi.org/10.1111/j.1467-8276.2005.00826.x

Larson, D. F., \& Gurara, D. Z. (2013). A Conceptual Model of Incomplete Markets and the Consequences for Technology Adoption Policies in Ethiopia (Policy Research Working Paper Series No. 6681). The World Bank Development Research Group Agriculture and Rural Development Team. http://dx.doi.org/10.1596/1813-9450-6681

Marenya, P. P., \& Barrett, C. B. (2007). Household-level Determinants of Adoption of Improved Natural Resources Management Practices among Smallholder Farmers in Western Kenya. Food Policy, 32(4), 515-536. https://doi.org/10.1016/j.foodpol.2006.10.002

Mercier, P. (1968). Tradition, changement, histoire, les “Somba” du Dahomey septentrional. Paris, 538 p.

Mignouna, B., Manyong, M., Rusike, J., Mutabazi, S., \& Senkondo, M. (2011). Determinants of Adopting Imazapyr-Resistant Maize Technology and its Impact on Household Income in Western Kenya. AgBioforum, 14(3), 158-163.

Mitchell, W. P. (1991). Some Are More Equal Than Others: Labour Supply, Reciprocity, and Redistribution in the Andes. Research in Economic Anthropology, 13, 191-219. https://doi.org/10.1093/law-iic/9780198809722.016.0008.

Moore, M. P. (1975). Co-operative Labour in Peasant Agriculture. The Journal of Peasant Studies, 2(3), 270-291 https://doi.org/10.1080/03066157508437936.

Netting, R. M., Stone, M. P., \& Stone, G. D. (1989). Kofyar Cash-Cropping: Choice and Change in Indigenous Agricultural Development. Human Ecology, 17(3), 299-319. https://doi.org/10.1007/BF00889021

Padenou, G.-H., \& Pastor-Barrué, M. (2006). Architecture, Société et paysage Bétammaribé au Togo: Contribution à l'Anthropologie de l'habitat. Presses Univ. du Mirail.

Palm, C. A., Myers, R. J. K., \& Nandwa, S. M. (1997). Combined Use of Organic and Inorganic Nutrient Sources for Soil Fertility Maintenance and Replenishment. p. 193-217. In R.J. Buresh, P.A. Sanchez, and F. Calhoun (ed.) Replenishing Soil Fertility in Africa. SSSA Spec. Publ. 51. SSSA and ASA, Madison, WI. https://doi.org/10.2136/sssaspecpub51.c8.

Ponte, S. (2000). From Social Negotiation to Contract: Shifting Strategies of Farm Labor Recruitment in 
Tanzania Under Market Liberalization. World Development, 28(6), 1017-1030. https://doi.org/10.1016/s0305-750x(00)00012-7.

Shiraishi, S. (2006). From Beer to Money: Labor Exchange and Commercialization in Eastern Uganda. African Studies Quarterly, 9(1), 39-53.

Sommerfeld, J., Sanon, M., Kouyate, B. A., \& Sauerborn, R. (2002). Informal Risk-Sharing Arrangements (IRSAs) in Rural Burkina Faso: Lessons for the Development of Community-Based Insurance (CBI). The International Journal of Health Planning and Management, 17(2), 147-163.

https://doi.org/10.1002/hpm.661.

Stone, G. D., Netting, R. M., \& Stone, M. P. (1990). Seasonality, Labor Scheduling, and Agricultural Intensification in the Nigerian Savanna. American Anthropologist, 92(1), 7-23. https://doi.org/10.1525/aa.1990.92.1.02a00010

Suehara, T. (1983). The Labour Exchanges System in the Tembo. African Study Monographs, 3, 59-69.

Suehara, T. (2006). Labor Exchange Systems in Japan and DR Congo: Similarities and Differences. African Studies Quarterly, 9(1-2), 55-65.

Swindell, K. (1985). Farm Labour. Cambridge: Cambridge University Press https://doi.org/10.1080/03768358708439346

Takasaki, Y., Coomes, O. T., Abizaid, C., \& Brisson, S. (2014). An Efficient Nonmarket Institution Under Imperfect Markets: Labor Sharing for Tropical Forest Clearing. American Journal of Agricultural Economics, 96(3), 711-732. https://doi.org/10.1093/ajae/aat102.

Worby, E. (1995). What Does Agrarian Wage-Labour Signify? Cotton, Commoditisation and Social Form in Gokwe, Zimbabwe. The Journal of Peasant Studies, 23(1), 1-29. https://doi.org/10.1080/03066159508438597.

\section{Copyrights}

Copyright for this article is retained by the author(s), with first publication rights granted to the journal.

This is an open-access article distributed under the terms and conditions of the Creative Commons Attribution license (http://creativecommons.org/licenses/by/3.0/). 